\title{
ECONOMIA POLÍTICA DA COMUNICAÇÃo: UMA PERSPECTIVA LABORAL
}

\author{
VINCENT Mosco 1
}

\section{Introdução}

Este artigo começa por fornecer uma panorâmica da economia política no contexto dos estudos da comunicação. Esta perspectiva teórica tem orientado grande parte da investigação sobre o trabalho nas indústrias de comunicação e o papel da comunicação na criação de uma divisão internacional do trabalho. Tendo como base a minha investigação nesta área (Mosco, 1996), a primeira parte do artigo define o conceito de economia política e explicita o seu uso na investigação em comunicação; a segunda parte pretende repensar e renovar as raízes filosóficas e o terreno fundamental da economia política. Sugere-se ainda que esta abordagem pode ser usada para compreender o trabalho. A altura é propícia para esta reflexão pois as transformações na economia política mundial e na vida intelectual colocam desafios fundamentais à economia política. As transformações na economia política mundial incluem a morte do comunismo, a estagnação das sociedades capitalistas, a dissolução de qualquer unidade que possa ter existido no chamado Terceiro Mundo e o surgimento de movimentos sociais, em particular do femininismo e do ambientalismo, que ultrapassam os limites de categorias político-económicas tradicionais como a classe social.

De entre os inúmeros desafios intelectuais que se deparam à economia política, há dois que se salientam pela sua relevância no estudo do trabalho

1 Professor de Comunicação na Escola de Jornalismo e Comunicaçāo, Carleton University. 
nas indústrias de comunicação. Por um lado, os estudos culturais (cultural studies) desafiam o terreno institucional da economia política e põem em causa a centralidade do trabalho como força histórica fundamental. Por outro lado, uma outra perspectiva, por vezes, denominada ciência política, teoria da escolha pública (public choice theory), expectativas racionais ou economia política "positiva», aplica a teoria económica neoclássica ao comportamento social e, desse modo, reduz o trabalho a um elemento entre muitos outros no mercado pluralista da escolha individual.

\section{O que é a economia política?}

Duas definições de economia política cobrem o vasto leque de abordagens específicas e gerais à disciplina. Em sentido restrito, economia política é o estudo das relações sociais, em especial das relações de poder, que constituem a produção, distribuição e consumo de recursos, incluindo os recursos da comunicação. Esta formulação é importante, porque chama a atenção para o circuito institucional dos produtos das comunicações que liga, por exemplo, uma cadeia de produtores iniciais a distribuidores, retalhistas e consumidores, cujas aquisiçōes, alugueres e cuidados vão alimentar novos processos de produção. No entanto, a ambiguidade acerca do que constitui um produtor, distribuidor ou consumidor justifica que se tenha algum cuidado com o seu uso. Uma definição mais abrangente e ambiciosa de economia política é o estudo do controle e sobrevivência na vida social. Controle refere-se especificamente à organização interna dos elementos dos grupos e ao processo de adaptação à mudança. Sobrevivência significa a forma como eles produzem o que é necessário para a reprodução e continuidade social. Nesta leitura, os processos de controle são, de um modo geral, políticos, já que constituem a organização social das relações dentro de uma comunidade e os processos de sobrevivência são fundamentalmente económicos porque se referem aos processos de produção e reprodução. O ponto forte desta definição é o facto de ela dar à economia política espaço para compreender, no mínimo, toda a actividade humana, nomeadamente todos os processos orgânicos, uma tendência reflectida nos estudos ambientais, ecológicos e de bio-diversidade (Benton,1989). No entanto, isso pode levar-nos a esquecer aquilo que distingue a economia política humana, incluindo o trabalho humano, que apenas abrange o poder de uma consciência orientada para um determinado fim efectivamente consciente da sua própria consciência, dos processos gerais de sobrevivência e controle.

Outra forma de descrever a economia política é a de estender o seu significado para além do que é tipicamente considerado nas definições, centrando-se num conjunto de qualidades que caracterizam a abordagem. 
Tendo por base o trabalho de Golding e Murdock (1991), este ponto centrase em quatro ideias - transformação social, totalidade social, filosofia moral e praxis - que diferentes correntes do pensamento político-económico tendem a partilhar.

A economia política tem constantemente salientado o objectivo de compreender a mudança social e a transformação histórica. Para os economistas políticos clássicos, como Smith, Ricardo e Mill, isto significava compreender a grande revolução capitalista, a vasta convulsão social que transformaria as sociedades inicialmente assentes no trabalho agrícola em sociedades comerciais, de transformação e, por fim, industriais. Para Marx, significava observar as forças dinâmicas dentro do capitalismo e entre este e outras formas de organização político-económica, de modo a compreender os processos da mudança social que iriam, por fim, transformar o capitalismo em socialismo. A economia ortodoxa, que começou a emergir em oposição à economia política no final do século XIX, tendia a colocar de lado esta preocupação com a dinâmica da história e a mudança social para transformar a economia política na ciência da economia, cujas afirmações em forma de leis eram mais adequadas para satisfazer condições sociais estáticas do que dinâmicas. Os economistas políticos contemporâneos, ocupando várias posições heterodoxas distintas daquilo que se tornou a ortodoxia económica, prosseguem a tradição de se interessarem pela transformação social. Humilhados por um século que provou ser errada uma atitude perante a história que E.P.Thompson caracterizava como «a condescendência massiva da posteridade», tendem mais modestamente a centrar a atenção à volta de vários "pós», em particular, o pós-fordismo, pós-industrialismo e pós-modernismo.

A economia política caracteriza-se, igualmente, por um interesse em estudar o todo social ou a totalidade das relações sociais que formam os campos económico, político, social e cultural. A ortodoxia académica tende a separá-los em diferentes disciplinas, cada uma com as suas próprias regras de entrada, controlos de fronteiras e sistemas de vigilância global. O pensamento pós-estruturalista actualmente em voga, embora louvável no seu ataque a esta e outras ortodoxias, também tende a negar a existência de totalidades sociais, ou mesmo discursivas, que lutam por princípios de ordem na vasta gama de práticas sociais quotidianas. Desde a época de Adam Smith, cujo interesse em compreender a vida social não era condicionada por fronteiras disciplinares, passando por Marx e até pelos teóricos institucionais, conservadores e neo-marxistas contemporâneos, a economia política tem constantemente visado a união do político e do económico dando conta da sua constituição mútua e da sua relação com esferas sociais e simbólicas mais amplas.

A economia política é igualmente conhecida pela sua ligação com a filosofia moral, entendida como um interesse quer pelos valores que 
ajudam a formar o comportamento social, quer, normativamente, pelos princípios morais que deveriam guiar os esforços para o mudar. Para Adam Smith, como testemunha a sua Teoria dos Sentimentos Morais (1976 (1759)), um livro que ele preferia ao popular A Riqueza das Nações (1937 (1776)), isto significava compreender valores como o consumismo e a liberdade individual, que estavam a contribuir para o advento do capitalismo comercial. Enquanto que para Marx $(1973,1976)$ filosofia moral significava a permanente luta entre o impulso de encontrar valor individual e social no trabalho humano e o impulso de reduzir o trabalho a uma mercadoria comercializável, a economia política contemporânea tende a centrar-se em pontos de vista filosófico-morais que enfatizam a extensão da democracia para além do domínio político, onde é muitas vezes legitimada em instrumentos legais formais para abranger os domínios económico, social e cultural que tendem a ser condicionados pelas necessidades de capital.

Decorrendo desta perspectiva, a praxis social, ou a união fundamental da teoria e da prática, ocupa igualmente um lugar central na economia política. Inequivocamente contra as posições ortodoxas que separam, pelo menos formalmente, a esfera da investigação da esfera da intervenção social, os economistas políticos, numa tradição que encontra as suas raízes na prática de aconselhamento a líderes políticos, têm persistentemente percepcionado a vida intelectual como uma forma de transformação social e a intervenção social como uma forma de conhecimento. Embora discordem radicalmente em relação àquilo que deve caracterizar a intervenção, desde Malthus que defendia a abertura dos esgotos de Londres para controlar os pobres até Marx que esperava que o trabalho se concretizasse na revolução, os economistas políticos partilham a opinião de que a divisão entre investigação e acção é artificial e deve ser abolida.

A economia política distingue-se igualmente pelas várias escolas de pensamento, que garantem uma variedade significativa de pontos de vista e um aceso debate interno. A principal cisão resultou das respostas à economia política clássica de Smith e seus discípulos. Um grupo pretendia retomar a ênfase tradicional no indivíduo como primeiro elemento de análise e no mercado como principal estrutura, participando ambos no processo central: a decisão individual como forma de expressão do desejo e da procura no mercado. Com o decorrer do tempo, esta resposta eliminou gradualmente as preocupações clássicas com a história, a totalidade social, a filosofia moral e a praxis de forma a transformar a economia política na ciência da economia baseada na investigação empírica do comportamento de mercado conceptualizada na linguagem matemática. Esta abordagem geralmente conhecida como economia neoclássica ou simplesmente economia, em reconhecimento da sua posição dominante - reduz o trabalho a um dos factores de produção que, juntamente com a terra e o capital, é valorizado apenas pela sua produtividade, ou pela capacidade 
de aumentar o valor de mercado de um produto final (Marshall, 1961 (1890); Jevons, 1965).

Um segundo grupo ou segundo conjunto de respostas opunha-se a esta tendência, mantendo a clássica preocupação com a história, o todo social, a filosofia moral e a praxis, mesmo que isso implicasse desistir do objectivo de criar uma ciência exacta. Este grupo apresenta uma grande variedade de abordagens da economia política. Um primeiro movimento foi liderado por neo-Burkeanianos conservadores, que substituíram o individualismo de mercado pela autoridade colectiva da tradição (Carlyle, 1984), por socialistas utópicos que aceitavam a fé clássica na intervenção social mas ansiavam por colocar a comunidade à frente do mercado (Owen, 1851), e pelo pensamento marxista que recolocou o trabalho no centro da economia política. De acordo com este último, o Homo Faber definia a nossa característica fundamental como espécie, nomeadamente a inigualável união da concepção e da execução que distinguia, no exemplo de Marx, o arquitecto da abelha. Formulações posteriores desenvolveram estas perspectivas, deixando-nos uma vasta gama de concepções contemporâneas. Embora a ciência económica ortodoxa ocupe o centro e centro-direita da faixa intelectual, uma economia política conservadora prospera no trabalho de gente como George J. Stigler (1988), James M. Buchanan (Brennan and Buchanan, 1985), e Ronald Coase $(1968,1991)$, recentemente premiados com o Nobel da economia, que aplicam as categorias da economia neoclássica a todo o comportamento social com o objectivo de expandir a liberdade individual. A economia política institucional ocupa uma posição ligeiramente à esquerda do centro (centro-esquerda), argumentando, por exemplo, no trabalho de Galbraith (1985) - que se inspirou principalmente em Veblen (1934 (1899), 1932) - que os condicionalismos institucionais e tecnológicos condicionam os mercados a favor daquelas empresas e governos que têm o poder para os controlar. Entre outras coisas, os institucionalistas elaboraram histórias económicas do trabalho e dos sindicatos que puseram em causa a limitada concepção individualista dos economistas neo-clássicos. As correntes neo-marxistas, incluindo a Escola Francesa da Regulação (Lipietz, 1988), a teoria dos sistemas-mundo (Wallerstein, 1979) e outras empenhadas no debate sobre o fordismo (Foster, 1988), continuam a colocar o trabalho no centro de análise e sāo particularmente responsáveis por debates sobre a relação entre capitalismo monopolista, a eliminação da especialização e o crescimento de uma divisāo internacional do trabalho. Por último, os movimentos sociais geraram as suas próprias escolas de economia política, principalmente a economia política feminista, a qual dirige a sua atenção para a persistência do patriarcado e o desinteresse pelo trabalho doméstico (Waring, 1988), e a economia política ambiental que se concentra nas ligações entre comportamento social e o ambiente orgânico mais vasto (Bentos, 1989). 


\section{A Economia Política da Comunicação}

Os estudos da comunicação basearam-se nas várias escolas de análise político-económica. Este ponto centra-se em investigações situadas nas abordagens institucionais e neo-marxistas, já que estas têm prestado maior atenção ao trabalho nas indústrias de comunicação e ao impacto da comunicação nas transformações contemporâneas no trabalho. Embora tanto os economistas neoclássicos (Owen e Wildman, 1992) como os economistas políticos conservadores (Coase, 1968) tenham teorizado sobre as indústrias de comunicação, nenhum deles incluiu o trabalho nas suas análises.

No estádio actual do seu desenvolvimento, seria útil traçar o mapa da economia política da comunicação através das diferentes regiōes. Embora existam importantes excepções e contra-correntes, as abordagens norteamericana, europeia e do chamado Terceiro Mundo diferem o suficiente para serem tratadas de forma distinta. Além disso, a abordagem da economia política à comunicação não está suficientemente desenvolvida teoricamente para ser explicada num único mapa analítico.

A investigação norte-americana tem sido largamente influenciada pelos contributos de duas figuras fundadoras, Dallas Smythe e Herbert Schiller. Smythe leccionou o primeiro curso de economia política da comunicação na Universidade de Illinois e é o primeiro de quatro gerações de estudiosos que se têm dedicado a esta tradição de investigação ${ }^{2}$. Schiller, que trabalhou durante algum tempo com Smythe em Illinois, tem igualmente influenciado várias gerações de economistas políticos. A abordagem destes aos estudos da comunicação baseia-se tanto na tradição institucional como na marxista. Contudo, interessaram-se menos do que, por exemplo, os estudiosos europeus em fornecer uma explicação teórica da comunicação. O seu trabalho - e, através da sua influência, grande parte da investigação nesta região - tem sido guiado mais explicitamente por um sentido de injustiça de que a indústria da comunicação se tornou parte integrante de uma grande ordem corporativa que é simultaneamente exploradora e anti-democrática. Embora se tenham interessado pelo impacto dentro dos seus respectivos países, ambos lideraram um programa de investigação que traça o crescimento em poder e influência das empresas de comunicação social transnacionais por todo o mundo (Smythe, 1981; Schiller, 1969 (1992), 1996).

Em parte devido à influência destes autores, a investigação norteamericana produziu uma vasta literatura sobre a indústria e sobre mani-

2 Um aluno de Smythe, Thomas Guback reformou-se recentemente da Universidade de Illinois onde se dedicava à economia política do cinema. Janet Wasko, aluna de Guback, trabalha igualmente nesta área na Universidade de Oregon, enquanto um seu aluno, Jack Banks se dedica a investigaçāo sobre economia política da música na universidade de Hartford. 
festações específicas de classe nas empresas transnacionais e no poder do estado, reconhecidas pela sua preocupação em participar em lutas contínuas, incluindo as do trabalho para mudar os media dominantes e para criar alternativas (Douglas, 1986; Mosco and Wasco, 1983; Wasco and Mosco, 1992; Schiller, 1996). Um dos principais objectivos desse trabalho é o de avançar com preocupações de interesse público perante aos órgãos reguladores e políticos do Estado. Isso inclui o apoio aos movimentos que desempenharam um papel activo perante os forums internacionais, como as Nações Unidas, em defesa de uma nova ordem internacional económica, de informação e de comunicação (Roach, 1993).

A investigação europeia não está tão claramente ligada a figuras fundadoras e, embora também esteja relacionada com movimentos para a transformação social, particularmente a defesa do serviço público dos meios de comunicação social, o trabalho de maior significado nesta região tem procurado essencialmente integrar a investigação em comunicação dentro de várias tradições teóricas neo-marxistas. Das duas principais direcções que esta investigação tomou, uma, mais proeminente nos trabalhos de Garnham (1990) e Golding e Murdock (1991), (Murdock e Golding, 1979), enfatizou o poder de classe (class power). Baseando-se na tradição da Escola de Frankfurt, bem como no trabalho de Raymond Williams, ela documenta a integração das instituições ligadas à comunicação, principalmente as autoridades de negócios e de decisão do Estado, na grande economia capitalista, e a resistência das classes e movimentos subalternos que se reflecte essencialmente em oposição a práticas governamentais neo-conservadoras promovendo a liberalização, comercialização e privatização das indústrias de comunicação. Uma segunda corrente de investigação, mais proeminente no trabalho de Armand Mattelart (1992 (1986), 1983), coloca a luta de classes em primeiro plano. Mattelart partiu de um conjunto de tradiçōes que incluíam a teoria da dependência, o marxismo ocidental e a experiência mundial de movimentos de libertação nacional para entender a comunicação como uma das principais fontes de resistência ao poder.

Entre os vários estudos sobre o poder de classes especificamente direccionados para um entendimento do trabalho sob esta perspectiva, Miège (1989) fornece uma avaliação de diferentes processos de trabalho, que tendem a ser coerentes com diferentes formas de produção dos media dentro da lógica global das relações sociais capitalistas. Ele sugere que existe uma relação entre o tipo de produto mediático, a estrutura de controle corporativo e a natureza do processo de trabalho. Os equipamentos mediáticos, como os aparelhos de televisão e gravadores, caracterizam-se por um processo simples de produção com pouca intervenção de trabalhadores criativos ou artísticos. Segundo esta perspectiva, estes produtos mediáticos prestam-se à concentração industrial e a um processo de trabalho detalhado, incluindo uma divisão internacional do trabalho 
que tira partido dos baixos salários pagos a trabalhadores não-sindicalizados, sujeitos a um regime de controle autoritário. No lado oposto do espectro está um segundo tipo de produto com características artísticas; aquilo que ele chama «realizações audio-visuais» é produzido quase exclusivamente com trabalho artesanal, de difícil reprodução, e requerendo injecções de capital relativamente baixas. Isto sustenta um sector dominado por pequenos negócios e permite a presença permanente do produtor ou o controle do trabalho. Miège identifica um último tipo de produto como um elemento de luta e conflito por ser fácil de reproduzir e simultaneamente exigir algum nível de contribuição artística. Este sector contém um crescente, mas longe de ser completo, controle monopolista e uma grande variedade de mão-de-obra, o que contribui para o desenvolvimento de tensões e conflitos, bem como entre capital e trabalho. A investigação sobre o trabalho e a luta de classes foi proeminente no trabalho de Peter Waterman $(1990,1992)$ que documentou o uso dos mass media e das novas tecnologias de comunicação por parte dos trabalhadores e dos sindicatos para promover a democracia e o internacionalismo.

No chamado Terceiro Mundo, a investigação sobre a economia política da comunicação cobre uma vasta área de interesses, embora uma corrente principal se tenha desenvolvido em resposta à modernização ou paradigma desenvolvimentalista que originou no ocidente, particularmente nos Estados Unidos, tentativas de incorporar a comunicação num paradigma explicativo favorável aos interesses intelectuais e políticos dominantes. A tese defendia que os media eram recursos que, juntamente com a urbanização, a educação e outras forças sociais, estimulariam a progressiva modernização económica, social e cultural. Como consequência, o crescimento dos media era visto como um indicador de desenvolvimento. Apoiando-se na dependência, nos sistemas-mundo e outras correntes da economia política neo-marxista internacional, os economistas políticos do Terceiro Mundo questionaram as premissas fundamentais do modelo, em especial o seu determinismo tecnológico e a omissão de praticamente todo o interesse nas relações de poder que condicionam os termos das relações entre as nações de Primeiro e Terceiro Mundos e as relações que dentro delas se verificam ao nível das relações entre os vários estratos sociais (Cardoso, 1979, Roncaglio, 1986, 1991, Tang and Chan, 1990). O fracasso dos planos de desenvolvimento que incluíam investimento dos media colocou os teóricos da modernização em busca de modelos revistos que tenderam a incorporar as telecomunicações e as novas tecnologias informáticas no seu conjunto (Jussawalla, 1986). Os economistas políticos responderam direcionando o poder destas novas tecnologias para uma divisão global do trabalho. Uma corrente de investigação encarava a divisão essencialmente em termos territoriais: mão-de-obra não especializada concentrada nas nações mais pobres; trabalho de grupo mais complexo e 
semi-especializado nas sociedades semi-periféricas e investigação, desenvolvimento e planeamento estratégico limitados às sedes de empresas do Primeiro Mundo onde os lucros aumentariam. Uma segunda corrente reconhece que as divisões de classes atravessam os limites territoriais e sustenta que o essencial para a divisão internacional do trabalho em desenvolvimento é o aumento da flexibilidade nas empresas que controlam o conjunto de tecnologias que superam os condicionalismos de tempo e espaço (Morris-Suzuki, 1986, Harvey, 1989, Sivanandan, 1989; Sussman and Lent, 1998).

\section{Repensando a Economia Política}

Embora muitas avaliações da economia política (incluindo a sua aplicação à investigação em comunicação) reconheçam o seu contributo para a vida intelectual e para as lutas políticas, elas também levantam preocupações acerca da necessidade de repensar e renovar a disciplina à luz das recentes transformações. Este ponto responde a esta efervescência geral sugerindo pontos de partida para repensar a economia política que podem guiar a investigação em comunicação, incluindo a relação com o trabalho.

As bases filosóficas de uma abordagem da economia política à comunicação fornecem um ponto de partida importante. Baseando-me numa literatura crítica que reflecte sobre o estado deste campo, adianto princípios básicos epistemológicos e ontológicos (Golding and Murdock, 1991; Gandy, 1992; H. Schiller, 1996). Uma epistemologia é uma teoria da teoria ou uma abordagem para compreender um campo de conhecimento. A economia política da comunicação necessita de ser fundamentada numa epistemologia realista, inclusiva, constitutiva e crítica. É realista no sentido em que reconhece a realidade tanto dos conceitos como das práticas sociais, evitando desse modo abordagens ideográficas e nomotéticas, actualmente em voga no pensamento pós-estruturalista, as quais defendem, respectivamente, apenas a realidade do discurso ou a rejeição das premissas da realidade tanto do discurso como das práticas sociais. Decorrendo disto, a abordagem é inclusiva no sentido em que rejeita o essencialismo, o qual reduziria todas as práticas sociais a uma única explicação político-económica, a favor de uma abordagem que vê os conceitos como pontos de entrada num campo social (Resnick e Wolff, 1987). A escolha de determinados conceitos e teorias em vez de outros significa dar prioridade a uns em detrimento dos outros como instrumentos úteis de explicação. Não se trata de meras imposições do melhor ou do único modo de compreender as práticas sociais. Adicionalmente, a epistemologia é constitutiva no sentido em que reconhece os limites da determinação causal, incluindo a suposição de que as unidades de análise social interagem como conjuntos completa- 
mente formados e de uma maneira linear. Ela aborda antes o social como um conjunto de processos mutuamente constitutivos, agindo uns sobre os outros em variados estados da formação e com uma direcção e impacto que apenas pode ser compreendida em investigação específica. Por último, a abordagem é crítica no sentido em que o conhecimento, a constituição mútua da teoria e da prática, é visto como o produto de permanentes comparações com outros corpos do saber e com um conjunto de considerações normativas que regulam a praxis social. Por exemplo, a minha economia política é crítica no sentido em que ela situa regularmente o conhecimento adquirido na investigação face a corpos de conhecimento alternativos na economia neoclássica, na ciência política pluralista e nos estudos culturais. Além disso, ela mede o conhecimento político-económico de acordo com os valores da social-democracia, incluindo a participação pública e igualdade que guiam a minha praxis.

Ligada a esta abordagem epistemológica está uma ontologia que coloca em primeiro plano a mudança social, o progresso social e as relações sociais contra a tendência da investigação social, particularmente na economia política, de se concentrar nas estruturas e instituições. Isto significa que a investigação parte do princípio de que a mudança social é omnipresente, que as estruturas e instituições estão num processo de mudança constante e que é, por isso, mais útil desenvolver pontos de entrada que caracterizem os processos do que nomear as instituiçōes. Guiado por este princípio, desenvolvo um mapa da economia política com três processos de entrada: a commodification ("comodificação») processo de transformação da utilidade em valor de troca; a espacialização, a transformação do espaço com o tempo ou o processo do alargamento institucional; e a estruturação, o processo de constituição de estruturas com agências sociais. Destacar a mudança social com estes processos não substitui as estruturas e instituições, algo que substituiria uma forma de essencialismo por outra. Pelo contrário, estes são pontos de entrada que constituem uma teoria concreta da economia política, uma escolha eleita de entre um conjunto de meios possíveis para compreender o campo social. Na próxima etapa, trabalha-se com estes pontos de entrada concretos, usando-os para sugerir as fronteiras de uma análise político-económica e, mais especificamente, para compreender o trabalho e a sua divisão internacional na investigação em comunicação.

A «comodificação» há muito tempo que é entendida como o processo de "pegar» em bens e serviços que são valorizado pela sua utilidade — por exemplo, na comida para satisfazer a fome - transformando-os em mercadorias que são valorizados por aquilo que podem render no mercado. O processo de «comodificação» possui uma dupla importância para a investigação em comunicação. Em primeiro lugar, as práticas e tecnologias da comunicação contribuem para o processo geral de «comodificaçăo" na 
sociedade. Por exemplo, a introdução da comunicação informática dá às empresas um maior controle sobre todo o circuito de produção, distribuição e troca, permitindo aos retalhistas monitorizar as vendas e os níveis de stock com uma precisão cada vez maior e, desse modo, produzir e colocar no mercado apenas aquilo que tem probabilidades de vender rapidamente, reduzindo as falhas de stocks e mercadorias desnecessárias. Em segundo lugar, a "comodificação» é um ponto de entrada para compreender instituições e práticas de comunicação específicas. Por exemplo, a expansão mundial da "comodificação" na década de 80 , reagindo em parte aos declínios globais no crescimento económico, levou a um aumento da comercialização da programação, à privatização dos meios de comunicação social e das instituições de telecomunicações e à liberalização dos mercados da comunicação.

A economia política da comunicação tem-se destacado pela sua preocupação de descrever e observar a importância das formas estruturais responsáveis pela produção, distribuição e troca dos produtos de comunicação e pela regulação do mercado da comunicação. Embora não tenha negligenciado o produto em si nem o processo de «comodificação", a tendência tem sido a de colocar em primeiro plano as estruturas e instituições corporativas e públicas. Depois de ter considerado o produto, a economia política tendeu a concentrar-se no conteúdo dos media, e em menor medida nas audiências mediáticas, prestando surpreendentemente pouca atenção ao trabalho. A ênfase dada às estruturas e conteúdos dos media é compreensível à luz da importância das companhias mundiais de comunicação social e do aumento do valor do conteúdo dos media. As empresas transnacionais fortemente integradas, como a Time Warner Corporation, criam produtos mediáticos de efeito multiplicador. Por exemplo, um filme lançado nos Estados Unidos é inicialmente exibido nas salas de cinema deste país e no estrangeiro; cerca de seis meses depois, é lançado em vídeo e posteriormente em pay-per-view. Tendo ainda passado nos canais de cabo, o produto poderá ainda chegar à televisão terrestre (via hertziana).

A economia política tem prestado alguma atenção às audiências, particularmente ao esforço de compreender a prática comum dos anunciantes pagarem pela quantidade e qualidade de uma audiência de um jornal, revista, rádio ou programa de televisão. Isto gerou um aceso debate para determinar se as audiências, na realidade, funcionam, i.e. se vendem a sua atenção em troca de conteúdos produzidos (Smythe, 1977; Murdock, 1978). O debate tem sido útil porque alargou a discussão para além do conteúdo e integrou os anunciantes, os representantes habituais do capital no âmago da investigação em comunicação. Por outro lado, o debate desencorajou os economistas políticos da investigação mediática (media research), porque não dava atenção consistente à "comodificação» e ao trabalho, o último 
historicamente entendido como incluindo aquele que perdeu progressivamente o controle sobre os meios de produção e foram consequentemente deixados apenas com a sua capacidade de trabalho que vendem por um salário (Lebowitz, 1986).

Até à década de 70, com a possível excepção dos institucionalistas, o mesmo aconteceu com a investigação político-económica em geral. No sentido de examinar a "comodificação" dos produtos, as análises tendiam a negligenciar o trabalho enquanto mercadoria e o trabalho no processo da produção. A obra de Braverman (1974) deu origem a um movimento intelectual para acabar com esta situação marginal, confrontando directamente a transformação do processo de trabalho no capitalismo. Segundo ele, o trabalho é constituído a partir da unidade da concepção, a capacidade de prever, imaginar e conceber o trabalho, e da execução, a capacidade de o executar. No processo de "comodificação", o capital age no sentido de separar à concepção da execução, a competência da pura capacidade de executar uma tarefa, para concentrar a capacidade conceptual numa classe dirigente que é uma parte do capital ou representa os seus interesses, e para reconstituir o processo produtivo com esta nova distribuição de competência e poder no local de produção. No extremo desta tendência, e com considerável resistência dos trabalhadores, isto envolveu a aplicação das chamadas práticas de gestão científica, que tiveram em Frederick Winslow Taylor um pioneiro. Braverman documentou o processo de transformação do trabalho com o surgimento da grande indústria, mas é particularmente conhecido por ter produzido uma das primeiras análises sustentadas demonstrando a extensão deste processo aos sectores de serviços e informação. O seu trabalho deu origem a um enorme corpo de investigação empírica e debate teórico, concentrando-se principalmente na necessidade de se dedicar à natureza competitiva do processo e ao movimento sindical (Burawoy, 1979; Edwards, 1979), e, além disso, à forma como a transformação do processo produtivo foi sentida - de forma diferente - pela indústria, ocupação, classe, género e raça (Berberoglu, 1993).

A literatura na área da economia política apresenta algumas provas da influência deste trabalho, particularmente na investigação sobre a introdução das novas tecnologias de comunicação e informação e sobre a transformação do trabalho, incluindo modelos de emprego e a natureza mutável do trabalho na indústria da comunicação social e das telecomunicaçōes. Denunciando a ausência de uma perspectiva laboral na indústria do jornalismo, Hardt e Brennen (1995) pretendem completar aquilo que é uma perspectiva essencialmente económica com uma história cultural da redacção que se centra na apresentação de novas tecnologias para levarem a cabo os processos descritos por Braverman. Isto representa um alargamento do trabalho pioneiro de economistas políticos que, trabalhando fora dos estudos da comunicação, estudaram o processo de trabalho nas redacções 
(Zimbalist, 1979). Estudos mais recentes que, entre outras coisas, se referem à "comodificação" do trabalho na redaç̧ão, analisam a aplicação das novas tecnologias para reduzir o emprego na indústria e para restruturar o trabalho dos editores através da implementação da paginação electrónica e o dos repórteres através da recolha electrónica de notícias (Russial, 1989). Estes são usos específicos da visão do processo de trabalho que aponta para o uso de tecnologias de comunicação e informação que transfere o equilíbrio do poder na actividade conceptual dos jornalistas profissionais com algum controlo sobre os seus meios de comunicação, para sistemas tecnológicos controlados administrativamente. Investigações semelhantes começaram a focar a transformação do processo de trabalho no cinema (Clark, 1995), televisão (Wasko, 1983), telecomunicações (Mosco e Zureik, 1987) e as indústrias de informação (Kraft e Dubnoff, 1986). Como foi atrás referido, Miège (1989) faz uma análise diferente, unindo-se a um esforço para ligar a economia política e a investigação em comunicação organizacional (c.f. Fishman, 1980), sugerindo que existe uma ligação entre o tipo de produto mediático, a estrutura de controlo corporativo e a natureza do processo de trabalho.

O segundo ponto de entrada substantivo é a espacialização, ou o processo de vencer os constrangimentos do espaço e do tempo na vida social. Teóricos clássicos como Smith e Ricardo - em parte como resposta aos seus antecessores que defendiam que a terra era a fonte de todo o valor - julgaram necessário dispensar uma atenção considerável aos problemas de valorização do espaço. O seu desenvolvimento de uma teoria do trabalho deparou-se com o problema de definir e medir o tempo de trabalho. Marx aproximou-se daquilo que aqui nos interessa quando, no Grundrisse (1973), referiu que o capitalismo "aniquila o espaço e o tempo". Com isto ele queria dizer que o capital faz uso dos meios de transporte e comunicação para diminuir o tempo necessário para mover bens, pessoas e mensagens no espaço. Teóricos contemporâneos (Lash e Urry, 1987) modificam esta visão, sugerindo que o capital transforma o espaço em vez de o aniquilar. Eles recordam-nos que as pessoas, produtos e mensagens têm que estar em algum lugar e é este lugar que está a sofrer uma transformaçāo significativa, testemunhada, por exemplo, em convulsōes na divisão internacional do trabalho.

A espacialização é semelhante a conceitos fornecidos por geógrafos e sociólogos para se referirem às mudanças estruturais provocadas por alterações no uso do tempo e espaço. Giddens (1990) refere-se à distanciação tempo-espaço a fim de analisar o declínio da dependência tempo-espaço. Ele sugere que este processo expande a disponibilidade do tempo e espaço como recursos para aqueles que podem fazer uso deles. Harvey (1989) identifica a compressão tempo-espaço para sugerir como o mapa efectivo está a encolher mais uma vez para aqueles que podem tirar partido disso. 
Castells (1989) chama a nossa atenção para a importância decrescente do espaço físico, o espaço dos lugares e a importância crescente do espaço de fluxos para sugerir que o mapa do mundo está a ser redesenhado de acordo com fronteiras estabelecidas por fluxos de pessoas, bens e serviços, criando o que Massey (1992) chama de "geometria transformada do poder».

A comunicação é fulcral para a espacialização, porque os processos e tecnologias da comunicação e informação promovem a flexibilidade e controlo nos negócios, particularmente - dentro dos próprios negócios da comunicação e informação. A espacialização abrange o já gasto termo «globalização» que talvez seja mais adequado para análise da restruturação mundial de indústrias e empresas. A reestruturação ao nível da indústria é exemplificada pelo crescimento de mercados integrados assentes em tecnologias digitais e, ao nível das empresas, pelo seu crescimento flexível ou «virtual», que faz uso de sistemas de comunicação e informação para mudar constantemente a estrutura, linha de produção, marketing e relações com outras companhias, com fornecedores, com os seus trabalhadores e clientes (Shiller, 1999).

A globalização e reestruturação industrial influenciam mutuamente os modelos da reestruturação do Estado. Seguindo o trabalho de Murdock (1990), pode identificar-se quatro dimensões da transformada actividade do Estado. A comercialização estabelece as funções do Estado, como prestador de serviços de correios e telecomunicações, numa perspectiva meramente empresarial ou de geração de lucros. A privatização leva isto um pouco mais distante tornando estes serviços em negócios privados. A liberalização dá a aprovação do Estado à abertura dos mercados à competição e, por último, a internacionalização liga o Estado a outros estados de forma a transferir a autoridade económica e política para sistemas comerciais regionais (NAFTA) e internacionais (Organização Mundial do Comércio).

A economia política da comunicação aborda este processo essencialmente em termos da extensão institucional do poder corporativo na indústria da comunicação. Isto está patente no extraordinário crescimento das empresas de comunicação social, o que pode ser verificado pelo activo, pelos lucro, pelos funcionários ou pelo valor das acções. A economia política analisou especificamente o crescimento pegando em diferentes formas de concentração corporativa (Herman e Chomsky, 1988). A concentração horizontal tem lugar quando uma empresa de uma cadeia de comunicação social compra a maior parte de uma outra empresa de comunicação social que não está directamente relacionada com o negócio original ou quando adquire uma fatia maioritária numa empresa não ligada ao ramo da comunicação social. O exemplo típico da primeira, a concentração "cross media», é a aquisição por parte de uma cadeia mais antiga de comunicação social (ex: um jornal) de uma empresa de uma cadeia de rádio ou de televisão mais recente. A integração vertical designa a fusão de empresas dentro de 
uma cadeia de negócio que estende o controle de uma empresa a todo o processo de produção. A aquisição da Cineplex-Odeon pela Paramount deu a esta grande produtora de Hollywood o controlo sobre uma grande companhia de distribuição cinematográfica. Isto é igualmente designado por integração progressiva porque expande uma empresa até uma fase avançada do processo total. Integração vertical regressiva ocorreu quando The New York Times adquiriu fábricas de celulose no Quebec, expandindo assim a companhia para a fase inicial do processo produtivo. Os economistas políticos da comunicação dedicaram uma atenção significativa ao prolongamento da integração além fronteiras enquanto companhias como a Time-Warner, News Corporation, Disney, Microsoft, General Electric, entre outras, se transformam em conglomerados transnacionais que rivalizam em tamanho e poder com companhias de qualquer tipo de indústria. Elas começam a desenvolver formas flexíveis de poder corporativo evidenciado em «joint ventures", alianças estratégicas e outras formas de criação de equipas para projectos específicos a curto prazo, que unem companhias ou partes de companhias, incluindo concorrentes. Estes tiram partido de meios de comunicação mais flexíveis para se unirem e separarem quando o interesse mútuo o justifica.

A economia política deu também um passo em frente no que diz respeito à divisão internacional do trabalho e ao internacionalismo laboral (Sussman e Lent, 1998). Uma das consequências da espacialização é o desenvolvimento dos mercados globais do trabalho. As empresas podem agora tirar partido da diversidade de salários, níveis de especialização da mão-de-obra e outras características importantes a uma escala internacional. Grande parte dos primeiros trabalhos político-económicos, nesta área, centrava-se no alargamento da indústria de hardware (Sudeste asiático) e no crescimento da prestação de serviços de informação nas Caraíbas e outros países do chamado Terceiro Mundo onde as empresas eram atraídas pelos baixos salários e governos autoritários (Heyzer, 1986). Mais recentemente, o alcance da investigação expandiu-se no sentido de analisar o interesse crescente do capital em procurar no mundo menos desenvolvido fontes de salários relativamente baixos, mas māo-de-obra especializada, necessária em áreas como o desenvolvimento de software (Susman e Lent, 1998) e expandindo-se também para o mundo desenvolvido, onde um exemplo notável é o crescimento da produção americana de cinema e vídeo em Toronto, Vancouver e outras partes do Canadá. O crescimento da divisão internacional do trabalho na comunicação tem gerado interesse pelo internacionalismo do trabalho na comunicação (Jeong-Taik, 1988). Isto inclui fazer uso dos meios de comunicação, integrando as novas tecnologias, para criar ligações estreitas entre a classe trabalhadora e os interesses dos sindicatos além fronteiras (Waterman, 1990, Witheford, 1996). Também aqui, à semelhança de grande parte da literatura sobre a «como- 
dificação» do trabalho na comunicação, começou-se apenas por abordar aquilo que é um foco principal de atenção noutros campos da economia política. A economia política da comunicação precisa de resistir às compreensíveis tendências para o pensamento reducionista na literatura sobre a espacialização ao assumir uma perspectiva político-económica do nacionalismo e outras formas de localização. O mapa não está apenas a ser redesenhado para se ajustar às mudanças dos fluxos mundiais no espaço. A par da globalização, encontramos um nacionalismo a ressurgir e nacionalismos dentro do nacionalismo que contribuem para, e conflituam com, distintas tendências ao nível global. Finalmente, estes processos locais e nacionalistas necessitam igualmente de ser posicionados face ao socialismo, historicamente a alternativa original a uma economia política capitalista global (Ahmad, 1992).

O terceiro ponto de entrada é a estruturação, um processo que recebeu recentemente relevância no trabalho de Giddens (1984). A estruturação descreve a forma como a acção humana constitui estruturas que fornecem o próprio "medium» dessa constituição. Isto comporta uma interpretação contemporânea da noção marxista segundo a qual as pessoas fazem a história, mas não sob condições criadas por si próprias. $\mathrm{O}$ termo responde a preocupações com abordagens funcionalistas, institucionais e estruturalistas, surgidas da sua tendência de apresentar as estruturas como entidades determinantes completamente formadas.

Repensar a perspectiva da economia política significa alargar esta concepção com uma visão relacional de classe que a defina de acordo com as práticas e processos que ligam as várias classes. Nesta perspectiva, a classe trabalhadora não é definida simplesmente pela falta de acesso aos meios de comunicação, mas pelas suas relações de harmonia, dependência e conflito com classe capitalista. Além disso, uma concepção constitucional de classe vê a classe trabalhadora como produtora da sua própria identidade, mesmo que ténue, volátil e conflituosa, tanto na relação com o capital como independentemente dele. Os economistas políticos têm respondido timidamente a esta abordagem constitucional de classe, colocando em primeiro plano, por exemplo, a relação entre capital e trabalho e as formas como o trabalho se constitui dentro dessa relação e como força independente. Isto não retira o valor de analisar a classe, em parte, como um jogo de forças em equilíbrio ${ }^{3}$ que opõe quem tem a quem não tem recursos. A economia política da comunicação abordou a classe nestes termos produzindo investigação que documenta constantes injustiças nos sistemas de comunicação, particularmente no acesso aos meios de comunicação, e a proliferação destas injustiças nas instituições sociais (Golding e Murdock,

3 N.T. Zero-zum game no original 
1991; H. Schiller, 1996). Tal foi aplicado ao trabalho, em particular, na investigação sobre a forma como a tecnologia da comunicação e informação tem sido usada para automatizar e "despecializar" 4 , em vez de valorizar e, na expressão de Zuboff (1988), «informar» o trabalho (Webster e Robins, 1986). Tem sido igualmente usado para demonstrar como os meios de comunicação são utilizados para medir e "monitorar" a actividade laboral em sistemas de vigilância que estendem o controle administrativo a todo o processo laboral com precisão minuciosa (Clement, 1991). Mais recentemente, um corpo de literatura sobre a classe trabalhadora e o trabalho começou a dedicar-se a esta área com mais seriedade (c.f., por exemplo, McChesney, 1992). Efectivamente, existe uma necessidade premente de estudar os movimentos de classe contraditórios e alternativos, desde as lutas revolucionárias da América Latina, Ásia, África e Europa de Leste, em que os media são parte integrante dos processos, até aos media alternativos do Ocidente que fornecem uma visão sindicalista, socialista e distinta do senso comum capitalista. O objectivo é não entrar em celebrações românticas, mas, no mínimo, demonstrar como as classes se constituem, como fazem história, com base numa análise rigorosa dos factores que condicionam esta actividade.

Repensar a economia política significa também equilibrar outra tendência da economia política: quando tem dado atenção à agência (agency), processo e prática social, ela tende a centrar-se na classe social. Existem fortes razões para esta ênfase. A estruturação de classes é um ponto de entrada para compreender a vida social. Numerosos estudos têm documentado a persistência das divisões de classes na economia política da comunicação. Contudo, há outras dimensões da estruturação que complementam e entram em conflito com a estruturação de classes, incluindo o género (gender), raça e os genericamente definidos movimentos sociais, que, juntamente com a classe, constituem grande parte das relaçōes sociais da comunicação. Ao contrário de outras abordagens, a economia política não tem permanecido totalmente em silêncio no que respeita ao género, embora ela aborde habitualmente o assunto como uma dimensão das relações entre classes sociais. Isso aconteceu, por exemplo, na investigação sobre tecnologia de informação e divisão internacional do trabalho que aborda a dupla opressão que as mulheres enfrentam em indústrias como a de micro-electrónica, onde têm os salários mais baixos e as condições de trabalho mais brutais (Wright, 1987). Adicionalmente, ainda que os estudos das comunicações se tenham dedicado extensivamente à questão do imperialismo, analisando principalmente o papel dos meios de comunicação social e das tecnologias de informação na sua constituição, fizeram-no

4 N.T. Deskill no original. 
essencialmente para desenvolver a ideia do mundo dividido em classes, ou, embora menos frequentemente, como dividido por géneros. A divisão racial não tem sido considerada e, no entanto, as divisões raciais são a principal constituinte das múltiplas hierarquias da economia política global contemporânea. Além disso, raça - como categoria e relação social contribui fundamentalmente para o acesso aos recursos nacionais e globais, incluindo a comunicação, os media e a tecnologia da informação (Sivanandan, 1989, Ahmad, 1992).

A partir desta utilização da uso estruturação, poderíamos pensar na sociedade como conjunto de acções estruturalmente iniciadas por agentes que condicionam e são condicionados pela classe, género, raça e pelas relações dos movimentos sociais. De acordo com esta perspectiva, a sociedade existe - se não como um todo suturado - pelo menos como um campo no qual vários processos constituem mutuamente relações sociais identificáveis. Rejeita-se, portanto, a visão estruturalista de que o campo social é um continuum de subjectividades produzido por processos de categorização puramente nominais. Consequentemente, a classe, género e movimentos sociais são simultaneamente reais como relações sociais e como instrumentos de análise.

Uma das principais actividades na estruturação é o processo de construção da hegemonia, definida como algo incorporado e contestado como "natural», como senso comum, como forma de pensar sobre o mundo, incluindo tudo desde a cosmologia, passando pela ética até às práticas sociais quotidianas. A hegemonia é uma rede viva de significados e valores que se constituem mutuamente e que, ao serem experienciados como práticas sociais, parecem confirmar-se também mutuamente. Por exemplo, embora a economia política trate os agentes como actores sociais e não individuais, ela reconhece a importância do processo hegemónico da individualização. O conceito retirado de Poulantzas (1978) refere-se à prática de redefinição dos actores sociais, capital e trabalho, particularmente, como elementos individuais cujo valor está ligado aos direitos individuais, à expressão individual, ao exercício individual de responsabilidade política através do voto e à liberdade individual do consumo. Estas aç̧ões, tomadas em nome do Estado, mas ligadas ao exercício da classe, isolam os indivíduos uns dos outros, das suas identidades sociais e daqueles que detêm o poder de levar a cabo a individualização. Uma das principais tensões, conflitos e lutas dentro do processo de estruturação dá-se entre as tendências social e a tendência individualizadora. Em conclusão, das tensões e conflitos dentro de vários processos de estruturação, os media aparecem organizados nas suas formas dominantes, oposicionais e alternativas (Williams, 1975).

Repensar e renovar a economia política exige também que se olhe para a relação entre a disciplina e as disciplinas de fronteiras. Embora admi- 
tindo que se possa traçar o mapa do universo das disciplinas académicas de várias formas, seria útil que se situasse a economia política da comunicação face aos estudos culturais, por um lado, e face aos estudos políticos, por outro lado.

Os estudos culturais são um movimento intelectual com fundamentos muito genéricos que se centra na constituição de sentido nos textos, definidos genericamente para incluir todas as formas de comunicação social (During, 1993). A abordagem contém numerosas correntes e rupturas que alimentam um considerável crescimento no seu interior. Mesmo assim, pode contribuir de várias formas para o processo de renovação da economia política. Os estudos culturais têm estado sujeitos a uma crítica genérica do positivismo e a um esforço de constituir uma abordagem filosófica mais aberta que coloque em primeiro plano a constituição subjectiva e social do conhecimento. Têm igualmente tentado alargar a ideia daquilo que compreende a essência da análise cultural partindo da premissa de que a cultura é «vulgar», produzida por todos os actores sociais, e não apenas por uma elite privilegiada, e ainda de que o social se organiza à volta de divisões e identidades de género e nacionalidade tanto como de classe social. A economia política pode aprender algo a partir disto, mas pode igualmente contribuir para que os estudos culturais sejam repensados. Mesmo quando aceita uma abordagem filosófica aberta à subjectividade e mais genericamente inclusiva, a economia política insiste numa epistemologia realista que mantenha o valor das investigação histórica, do pensamento em termos de totalidades sociais concretas, de compromisso moral, e que ultrapasse a distinção entre investigação social e prática social. Ela afasta-se, portanto, da tendência dos estudos culturais à qual Pêcheux se refere como "o narcisismo do sujeito», bem como da inclinação para rejeitar o pensamento em termos de práticas históricas e totalidades sociais. A economia política afasta-se igualmente da tendência crescente para um obscurantismo nos estudos culturais que crê na perspectiva original de que a investigação cultural devia ser acessível às pessoas comuns que são responsáveis pela sua constituição. Por fim, evita a propensão dos estudos culturais para rejeitar os estudos laborais e o estudo dos processos laborais em favor da observação da "produção» social do consumo e da tendência para rejeitar o trabalho como possuidor de qualquer valor nos movimentos contemporâneos para a mudança social (Luke, 1989).

A economia política pode igualmente aprender com o desenvolvimento de uma perspectiva da ciência política cujo ramo político tem colocado o Estado no centro da análise e cujo braço económico tem aplicado a teoria económica neoclássica a uma vasta área da vida política, social e cultural (Stigler, 1988; Posner, 1992). A economia política tem procurado «ler» o Estado a outras forças «superestruturais» a partir da configuração específica do capital dominante e, por conseguinte, beneficia de uma abordagem 
que toma a sério o papel constitutivo do Estado. Além disso, a economia política partilha com a ciência política o interesse em estender a análise a toda a totalidade social, com um olhar para a transformação social. No entanto, a economia política destaca-se fundamentalmente da ciência política pluralista que vê o Estado como o árbitro independente de um vasto equilíbrio de força sociais que não param de oscilar; a economia política insiste no poder do capital e do processo da "comodificação" como ponto de partida da análise social. Além disso, a economia política rejeita a tendência da ciência política de basear a sua análise da totalidade social e dos valores que guiam a sua transformação no individualismo e no racionalidade de mercado (Radin, 1996). Contra esta perspectiva, a economia política insiste nos processos sociais, começando pela classe social e pelo trabalho, e coloca a comunidade e a vida pública face ao mercado e à racionalidade que efectivamente reproduz o poder das classes.

\section{BIBLIOGRAFIA}

AHMaD, Aijiz. In Theory: Classes. Nations. Literatures. London: Verso, 1992.

BENTON, Ted. «Marxism and Natural Limits: An Ecological Critique and Reconstruction» Left Review, No. 178, (Nov.-Dec., 1989), pp. 5 1-86.

Berberoclu, Berch. (Ed.) The Labor Process and Control of Labor Tbe Changing Nature of Work Relations in the, Late Twentieth Century. Westport, Conn.: Praeger, 1993.

BoAfo, S. T. Kwame.»Communication Technology and Dependent Development in Sub-Saharan Africa.» In Gerald Sussman and John A. Lent (eds.), Transnational Communications: Wiring the Third-World, Newbury Park: Sage, 1991, pp. 103-1 24.

Braverman, Harry. Labor and Monopoly Capital. New York: Monthly Review, 1974.

Brennan, Geoffrey and Buchanan, James M. The Reason of Rules, Constitutional Political Economy Cambridge University Press, 1985.

Burawoy, Michael. Manufacturing Consent. Chicago: University of Chicago Press, 1979.

CARDoso, F. H. and Faletro, E. Dependency and Development in Latin America. Berkeley: University of California Press, 1979.

CARLYLE, Thomas. A Carlyle, Reader. Edited by G. B. Tennyson, NY: Cambridge University Press, 1984.

CASTELLS, Manuel. The Informational City: Information Technology, Economic Restruc-turing and the Urban-Regional Process, Oxford: Basil Blackwell, 1989.

CLARK, Danae. Negotiating Hollywood: The Cultural Politics of Actor's Labor. Min-neapolis: The University of Minnesota Press, 1995.

ClemENT, Andrew. «Electronic Workplace Surveillance: Sweatshops and Fishbowls,» Canadian Journal of Information Science Vol. 17 (December), No. 4, pp. $18-45$. 
COASE, R. H. and BARRETT, Edward W. Educational TV: Who Should Pay? Wash-ington, D.C.: American Enterprise institute for Public Policy, 1968.

COASE, R. H. The Nature of the Firm: Origins. Evolution. And Development, edited by Oliver E. Williamson and Sidney G. Winter, NY: Oxford University Press, 1991.

Douglas, Sarah. Labor's New Voice: Unions and the Mass Media Norwood, New Jersey: Ablex, 1986.

DuRING, Simon (ed.). The Cultural Studies Reader. London: Routledge, 1993.

EDWARDS, Richard. Contested Terrain The Transformation of the Workplace on the Twentieth Century. NY: Basic, 1979.

Fishman, Mark. Manufacturing the News. Austin: University of Texas Press, 1980.

Foster, John Bellamy. "The Fetish of Fordism.» Monthly Review. Vol.39 (March), pp. 1 4-20.

GalbrarrH, John Kenneth. The New Industrial State. Fourth edition. Boston: Houghton Mifflin, 1985.

GANDx, Oscar, H. Jr. «The Political Economy Approach: A Critical Challenge,» Journal of Media Economics Summer, 1992, pp.23- 42.

GaRnham, Nicholas. Capitalism and Communication: Global Culture and the Economics of Information-, London: Sage, 1990.

GIDdEns, Anthony. The Constitution of Society: Outline of a Theory of Structuration. Berkeley: University of California Press, 1984.

The Consequences of Modernity. Stanford: Stanford University Press, 1990.

Golding, Peter and Murdock, Graham. "Culture, Communication, and Political Economy, in James Curran and Michael Gurevitch (eds.) Mass Media and Society, London: Edward Arnold, 1991, pp.15-32.

HARDT, Hanno and Brennan, Bonnie. Newsworkers: Toward a History of The Rank and File. Minneapolis: University of minnesota Press, 1995.

HaRVEY, David. The Condition Of Postmodernity. Oxford: Basil Blakwell, 1989.

HeRman, Edward S. and Noam Chomsky, Manufacturing Consent: The Political economy of the Mass Media, NY: Pantheon, 1988.

Heyser, Noeleen. Working Women in Southeast Asia: Development, Subordination, and Emancipation. Philadelphia, PA: Open University Press, 1986.

Jeong-TAIK, Lee. "Dynamics of Labor Control and labor Protest in the Process of ExportOriented Industrialization in South Korea." Asian Perspectives, vol. 12 (Spring-Summer, 1988), N. ${ }^{\circ} 1$.

Jevons, William Stanley. The Passing of Remoteness: the information Revolution in the AsiaPacific. Singapore: Institute of Southeast Asian Studies, 1986.

Kraft, Philip and Dubnoff, Steve. «Job Content, Fragmentation and Control in Computer. Software Work. «Industrial Relations. Vol. 25 (1986), pp. 184-196.

LASH, Scott and URRY, John. The End of Organized Capitalism. Madison, Wisconsin: University Wisconsin Press, 1987.

LebowITZ, Michael. «Too Many Blinspots on the Media» Studies in Political Eco-nomy, N. 21 August, 1986), pp. 165-173. 
LIPIETZ, Alain. «Reflections on a Tale: The Marxist Foundations of the Concepts of Regulation and Accumulation, "Studies in Political economy, 26, summer, 1988, pp. 7-36.

LUKE, Timothy. Screens of Power: Ideology, Domination, and resistance in Informational Society. Urbana and Chicago: University of Illinois Press, 1989.

MarSHall, Alfred. Principles of Economics. London: MacMillan, 1961 (1980).

MARX, Karl. Capital: A Critique of political economy. Vol. 1, Trans. By Bem Fowkes. London: Penguin, 1976.

- The Grundisse: Foundations of the critique of Political economy. Trans. By Martin Nicolaus, Harmondswoth: Penguin, 1973.

MASSEY, Doreen. «Politics and Space/Time. "New Left Review. N. 196 (November/ December, 1992), pp. 65-84).

MatTELART, Armand and Mattelart, Michèle. Rethinking Media theory: Signposts and New Directions. Trans. By James Cohen and Marina Urquidi, Minneapolis: University of Minnesota Press, 1992 (1986).

MaTTELART, Armand and seth Siegelaub, Communication and Class Struggle: Vol. 2 Liberation, Socialism, NY: International General, 1983.

MCCHESNEY, Robert W. Telecommunications, Mass media and democracy: The Battle for the Control of U.S. Broadcasting NY: Oxford, 1993.

MIÈGE, Bernard. The Capitalization of Cultural production, NY International Gene-ral, 1989.

Morris-SuzuKI, Tessa. "The Challenge of Computers» New Left Review, N. 160 (November/ December, 1986) pp. 81-91.

Mosco, Vincent. The Political Economy of Communication: Rethinking and Renewal. London: Sage, 1996.

Mosco, Vincent and WAsco, Janet. (eds.) The Critical Communications review, Vol. 1: Labor, the Working Class, and the Media. Norwood, New Jersey: Ablex, 1983.

Mosco, Vincent and ZUREIK, Elia. Computers in the Workplace: Technological Change in the Telephone Industry. Ottawa, Government of Canada, Department of Labour, 1987.

MURDock, Graham. «Redrawing the Map of the Communication industries,» in Marjorie Ferguson (ed.) Public Communication: The New imperatives. Beverly Hills: Sage, 1990, pp. 1-15

- Blindspots About Western Marxism: A Reply to Dallas Smythe.s Canadian Journal of Political and Social Vol. 2 (1978), No. 2.

Murdock, Graham and Peter Golding, "Capitalism, Communication, and Class Relations,» in James Curran, Michael Gurevitch and Janet Woolacott, Mass Communication and Society Beverly Hills: Sage, 1979, pp. 12-43.

OWEN, Robert. Labor: Its History and Prospects. NY, 1851.

OWEN, Bruce M. and WILDMAN, Steven S. Video Economics.Cambridge, MA: Harvard University Press, 1992.

PosNer, Richard A. Sex and Reason. Cambridge, MA: Harvard University Press, 1992.

Poulantzas, Nicos. State, Power, and Socialism. London: New Left Books, 1978.

RADIN, Margaret Jane. Contested Commodities Cambridge, MA: Harvard University Press, 1996. 
RESNICK, Stephen A. and Wolff, Richard D. Knowledge and Class A Marxian Critique of Political Economy. Chicago: University of Chicago Press, 1987.

ROACH, Colleen. (ed.) Communication and Culture in War and Peace. Newbury Park, CA: Sage, 1993.

RoNCAGLrolo, Rafael. "Transnational Communication and Culture." In Atwood, Rita and McAnany, Emile G. (eds.) Communication and Latin-American Society. Madison: University of Wisconsin Press, 1986, pp.79-88.

RUSSial, John T. Pagination and the Newsroom: Great Expectations. Doctoral dissertation completed in the School of Communication, Temple University, Philadelphia, PA, August, 1989.

SCHLLER, Dan. Theorizing Communication. NY: Oxford, 1996.

— Digital Capitalism. Cambridge, MA: MIT Press, 1999.

SCHILLER, Herbert I. Information Inequality_- NY: Routledge, 1996.

Mass Communication and American Empire. Boston: Beacon Press, 1969, Second edition updated, 1992.

Sivanandan, A. Communities of Resistance: Writings on Black Struggles for Socialism, London: Verso, 1990.

— New Circuits of Imperialism.» Race and Class. Vol. 30 (April-June, 1989), No. 4, pp. 1-19.

SMrTH, Adam. The Theory of Moral Sentiments, Indianapolis: Liberty Classics, 1976 (1759).

- An Inquiry into the Nature and causes of the Wealth of Nations NY: Modern Library, 1937 (1776).

SMYTHE, Dallas W. "Communications: Blindspot of Western Marxism.» Canadian Journal of Political and Social Theory. 1 (1 977),3, 1-27.

—Dependency Road Communication, Capitalism.Consciousness and Canada

NoRwood, New Jersey: Ablex, 1981.

STIGIER, George J. (ed.) Chicago Studies in Political Economy. Chicago: University of Chicago Press, 1988.

Sussman, Geraid and Lend, John (eds.) Global Productions: Labor in the Making of the 'Information Society.' Creskill, N.J.: Hampton, 1998.

TANG, Wing Hung and Chan, Joseph Man. «The Political Economy of International News Coverage: A Study of Dependent Communication Development.» Asian Journal of

Communication, Vol. 1 (1990), No. 1, pp. 53-80.

VEBLEN, Thorstein. The, Theory of the Leisure Class. NY: Modern Library, 1934 (1899).

The Theory of the Business Enterprise, NY: Scribner's, 1932.

WALLERSTEIN, Immanuel. The Capitalist World Economy. NY: Cambridge University Press, 1979. WARING, Marilyn. If Women Counted: A New Feminist Economics. NY: Harper Collins, 1988.

WaSko, Janet. "Trade Unions and Broadcasting.» In Vincent Mosco and Janet Wasko (eds.), The Critical,Communications Review. Vol,1:Labor, the Working Class and the Media. Norwood, New Jersey: Ablex, 1983, pp.85-113.

WASKo, Janet and Mosco, Vincent (Eds.). Democratic Communication in an Information Age, Toronto: Garamond and Norwood: Ablex, 1992. 
Waterman, Peter. "The Transmission and Reception of International Labour Information in Peru.» in Wasko and Mosco, 1992, pp.224-241.

- "Communicating Labor Internationalism: A Review of Relevant Literature and Resources." The European Joumal of Communication. Vol.15 (1990), No.1/2, pp.85-103.

WEBSTER, Frank and Robins, Kevin. Information Technology. ALuddite Analysis. Norwood, New Jersey: Ablex, 1986.

Williams, Raymond. Television, Technology and Cultural Form. London: Fontana, 1975.

WITHEFORD, Nicholas, The Contest for General Intellect: Cycles and Circuits of, Struggle in High Technology Capitalism, Doctoral dissertation, Simon Fraser University, Vancouver,1996.

WRIGHT, Barbara Drygulski, et al. (eds.) Women, Work, and Technology. Ann Arbor, Michigan: University of Michigan Press, 1987.

Zimbaust, Andrew. "Technology and the Labor Process in the Printing Industry» In Andrew Zimbalist (ed.) Case Studies an the Labor-Process. NY: Monthly Review, 1979, pp. 103-126.

ZUBoff, Shoshana. In the Age of the Smart Mahine. NY: Basic, 1988. 